\title{
Conhecimento sobre aleitamento materno de puérperas atendidas em dois hospitais de Viçosa, Minas Gerais
}

\author{
Knowledge about maternal nursing of mothers attended at two \\ hospitals in the city of Viçosa, Minas Gerais, Brazil
}

Nathércia PERCEGONI ${ }^{1}$

Raquel Maria Amaral ARAÚJO²

Margarida Maria Santana da SILVA²

Marilene Pinheiro EUCLYDES ${ }^{2}$

Adelson Luís Araújo TINÔCO²

RE S U M O

Este estudo teve como objetivo investigar o conhecimento de puérperas sobre o aleitamento materno. Foram entrevistadas 266 puérperas atendidas em dois hospitais da cidade de Viçosa, MG. A amostra caracterizou-se por mulheres na faixa etária de 13 a 48 anos, das quais 58,3\% residiam em Viçosa. A maioria delas tinha o $1^{\circ}$ grau incompleto. Segundo a pesquisa, $32,7 \%$ das mães receberam informação sobre amamentação antes do parto e $14,3 \%$ delas foram orientadas no pré-natal. Apesar de 99,2\% das entrevistadas manifestaram a necessidade de a criança ser amamentada, 54,8\% não conheciam outra função do leite além da alimentar. A sucção foi lembrada por apenas $1,5 \%$ das puérperas como fator que aumenta a produção de leite, e 61,0\% delas não conheciam a maneira correta de a criança abocanhar o mamilo. Quanto ao problema do ingurgitamento mamário, 57,0\% não sabiam como resolvê-lo. Com relação às leis de proteção à nutriz trabalhadora, $84,6 \%$ as desconheciam. Concluiu-se que o baixo nível de conhecimento, por parte das puérperas, sobre questões fundamentais para o sucesso da amamentação reafirmam a importância do incentivo e da orientação para o aleitamento durante o pré-natal.

Termos de indexação: aleitamento materno, mães, saúde infantil, comportamento materno.

\section{A B S T R A C T}

This study had the objective of investigating the mothers knowledge about maternal nursing. Two hundred and sixty-six mothers attended at two hospitals in the city of Viçosa, state of Minas Gerais, where interviewed.

\footnotetext{
1 Acadêmica, Curso de Nutrição, Universidade Federal de Viçosa. (Bolsista do PIBIC/CNPq).

2 Departamento de Nutrição e Saúde, Curso de Nutrição, Universidade Federal de Viçosa. Campus Universitário, s/n, 36571-000, Viçosa, MG. Correspondência para/Correspondence to: R.M.A. Araújo. E-mail: raraujo@mail.ufv.br
} 
The sample was characterized by women in the age group from 13 to 48 years old, and 58,3\% of them lived in Viçosa. The majority of them had not finished elementary school. From the total of mothers interviewed, $32.7 \%$ had received information on breast-feeding before the childbirth, and $14.3 \%$ of them were oriented in the prenatal period. Although of $99.2 \%$ of the mothers considered that the child should be breastfed, $54.8 \%$ did not know another function of milk besides feeding. The suction was remembered by only $1.5 \%$ of the mothers as a factor which increases the production of milk, and $61.0 \%$ of them did not know the child's correct way to seize the breast nipple with the mouth. Regarding the problem of mammary engorgement, $57.0 \%$ did not know how to solve it. Concerning the laws that favor the lactating workers, $84.6 \%$ ignored them. The mothers low level of knowledge about fundamental subjects for the breast-feeding success reaffirms the importance of the incentive and of the orientation towards nursing during the prenatal period.

Index terms: breast feeding, mothers, child health, maternal behavior.

\section{N T R O D U ÇÃ O}

O leite humano é indicado como o alimento ideal para a criança nos seus primeiros meses de vida, devido às suas propriedades nutricionais e antiinfecciosas, além das vantagens psicossociais da prática do aleitamento para a mãe e seu filho.

Embora o valor do leite materno para a saúde da criança e o seu benefício econômico para o país sejam inquestionáveis, o emprego da amamentação não ocorre de forma adequada, contribuindo, assim, para sua interrupção realizar-se cada vez mais cedo. O desmame precoce, principalmente em populações de baixa condição socioeconômica, expõe a criança a riscos de desnutrição e infecção, comprometendo seu crescimento e desenvolvimento.

No Brasil, tem-se procurado resgatar a prática do aleitamento materno através de várias propostas como o Programa Nacional de Incentivo ao Aleitamento Materno, em 1981, Pacto pela Infância no Brasil, em 1994, e a iniciativa mais recente: Hospital Amigo da Criança, destinado a estimular hospitais e maternidades a adotarem os "dez passos para o sucesso do aleitamento materno". Contudo, apesar de programas e profissionais de saúde incentivarem este procedimento, a interrupção precoce da amamentação continua a ocorrer de maneira significativa (Arantes,1995), tendo sido considerada uma das causas dos altos índices de mortalidade infantil verificados no país. Em 1996, a Pesquisa Nacional de Demografia e Saúde (PNDS) revelou uma diminuição muito rápida, no Brasil, do período de amamentação exclusiva, estando a mediana pouco acima de um mês (Pesquisa Nacional..., 1996).

Muitos fatores contribuem para o desmame precoce, no entanto, a falta de conhecimento sobre aleitamento materno por parte das mães tem representado papel importante na redução da duração desta prática. Esta carência de informação das mães é freqüentemente constatada em pesquisas as quais revelam entre as justificativas para o desmame afirmativas como: "o leite secou", ou "o leite é fraco, não sustenta", ou "o bebê chora muito". Carvalhais \& Simões (1997), quando citaram os fatores a interferirem no declínio da amamentação, incluíram o desconhecimento, por parte das mães, da técnica do aleitamento materno e de suas vantagens e benefícios. Também Giugliani et al. (1995) afirmaram encontrar-se entre as causas associadas à interrupção precoce da amamentação, a ausência de conhecimentos maternos sobre o assunto. Entretanto, deve-se ressaltar que não somente a falta de informação motiva o desmame precoce, mas também os aspectos sociais presentes no 
cotidiano da nutriz. Segundo Martins (1998), a amamentação, enquanto um fenômeno, vai além do discurso biológico; há questões sociais contidas no existir de cada mãe, muito relacionadas ao sucesso desta prática. Almeida (1999) chama a atenção para a importância de se compatibilizar os determinantes biológicos com os condicionantes socioculturais, pois a amamentação configura-se como uma categoria híbrida entre natureza e cultura.

Portanto, o diagnóstico da situação local, em relação aos conhecimentos das mães sobre o aleitamento materno, contribui para a determinação do direcionamento dos programas educativos e para a reorientação das práticas adotadas por profissionais e unidades de saúde.

Este estudo teve como objetivo investigar o conhecimento sobre o aleitamento materno de puérperas atendidas nos hospitais da cidade de Viçosa, MG.

\section{CASUÍSTICA E MÉTODOS}

Foram entrevistadas, no segundo dia pós-parto, 266 puérperas, que tiveram recém-nascidos normais e foram atendidas nos dois hospitais da cidade de Viçosa, MG, durante oito meses. A população estudada foi caracterizada quanto a idade, escolaridade, realização do pré-natal, paridade e residência.

Foi utilizada uma amostra aleatória simples, sendo estabelecidos, para definição do seu tamanho, um intervalo de confiança de $95 \%$, um nível de significância de 0,05 e uma prevalência prevista de $20 \%$ para os casos de puérperas internadas.

As variáveis estudadas foram orientações recebidas sobre o aleitamento materno e conhecimento das mães sobre aspectos deste procedimento, definidas com base no trabalho de Koch (1979).

Os dados foram obtidos por meio de entrevista individual, orientada por um questionário contendo doze perguntas relacionadas com o tipo e a procedência das informações recebidas sobre aleitamento materno e com a opinião da mãe sobre aspectos referentes à técnica de amamentação, à produção e liberação do leite materno, às suas propriedades e funções, aos benefícios desta prática e às leis que favorecem a nutriz trabalhadora.

\section{RESULTADOSE DISCUSS ÃO}

Parte considerável da população estudada (Tabela 1) residia em cidades vizinhas. Estas pessoas, carentes de um serviço de internação hospitalar em sua cidade, demanda esse serviço em Viçosa, MG.

Tabela 1. Ditribuição de puérperas atendidas nos hospitais, segundo a idade, escolaridade, realização do pré-natal, paridade e residência (Viçosa, MG, 1998).

\begin{tabular}{llc}
\hline Variáveis & & $\%$ Puérperas \\
\hline Idade & $<20$ anos & 25,0 \\
& $20-29$ anos & 53,0 \\
Escolaridade & $>29$ anos & 22,0 \\
& $1^{\circ}$ grau incompleto & 74,0 \\
& $1^{\circ}$ grau completo & 4,0 \\
& $2^{\circ}$ grau incompleto & 5,0 \\
& $2^{\circ}$ grau completo & 10,0 \\
Pré-natal & $3^{\circ}$ grau incompleto & 2,0 \\
& $3^{\circ}$ grau completo & 2,0 \\
Paridade & Analfabetas & 3,0 \\
& Fez pré-natal & 94,0 \\
Residência & Não fez pré-natal & 6,0 \\
& Primeito filho & 41,0 \\
& Mais de um filho & 59,0 \\
& Viçosa, MG & 58,3 \\
& Outras Cidades & 41,7 \\
\hline
\end{tabular}

A maior parte das puérperas estava entre 20 e 29 anos de idade; entretanto, um número considerável delas tinha menos de 20 anos. Tal fato pode significar prejuízo indireto à prática da amamentação, pois nesta faixa etária a maturidade fisiológica e emocional não foi plenamente atingida. Ressalta-se, no entanto, não ter sido encontrado por Xavier et al. (1991) associação entre a idade da mãe e a prática do aleitamento materno. 
O primeiro grau incompleto predominante entre as puérperas. Esta observação causa preocupação, considerando-se que a baixa escolaridade é um fator determinante da prática e continuidade da amamentação. Segundo Xavier et al. (1991), o nível de instrução materna indicou associação positiva com a incidência e duração do aleitamento materno. Além disso, Fadul \& Xavier (1983) relataram a ocorrência mais precoce de desmame em grupo de mães com apenas $1^{\circ}$ e $2^{\circ}$ graus.

Com relação aos conhecimentos anteriormente adquiridos, embora $94,0 \%$ das puérperas tenham feito o pré-natal, constatou-se elevado número de mulheres sem receber qualquer informação sobre aleitamento materno (67,3\%). Esta constatação é motivo de apreensão quando se observa, que $59,0 \%$ das mães tinham mais de um filho. Esta situação, a princípio, ampliaria a possibilidade de elas já terem recebido alguma orientação sobre esta prática (Tabela 1). Depreende-se, portanto, que a maioria das mulheres teve filhos sem receber preparação anterior para a amamentação. Segundo Giugliani et al. (1995), o desconhecimento sobre o aleitamento materno coloca em risco o sucesso da amamentação. Apenas 14,3\% das puérperas relataram ter recebido informação no pré-natal, mostrando a fraca contribuição dos serviços de saúde ao estímulo do aleitamento materno. Observação semelhante foi apresentada por Moura \& Araújo (1984), ao verificarem que

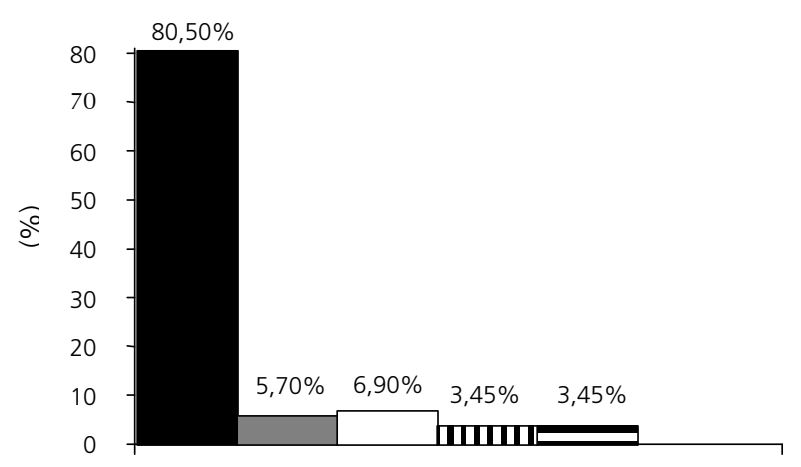

apenas $55,0 \%$ das mães acompanhadas no pré-natal disseram ser o leite humano o melhor alimento para seu filho. A influência positiva do incentivo ao aleitamento materno no pré-natal foi demonstrada por Kistin et al. (1990), em um estudo desenvolvido nos Estados Unidos no qual notou-se aumento de 22,0\% na incidência da amamentação após a introdução de aulas sobre este procedimento, durante o pré-natal. Valdés et al. (1996) atribuíram aos profissionais de saúde parte da responsabilidade pela diminuição da prática do aleitamento.

Com referência à importância do leite para a criança, 99,2\% das mães manifestaram a necessidade de a criança ser amamentada, indicando o reconhecimento do valor do leite materno para o bebê. Entre as informações recebidas a mais citada foi a de que o leite é o melhor alimento para o crescimento e desenvolvimento da criança (Figura 1).

Relativamente ao conhecimento sobre a prática da amamentação, observou-se desconhecimento por parte de $61,0 \%$ das puérperas da técnica correta de sucção do seio. Este resultado desperta para a possibilidade de dificuldades na prática do aleitamento. A criança, muitas vezes, não obtém a quantidade necessária de leite, pela sucção, por não estar abocanhando corretamente o mamilo (Brasil..., 1994). A mãe, por sua vez, interpreta erroneamente o choro da criança, atribuindo-o ao fato de ser fraco o leite produzido.

Figura 1. Distribuição de puérperas segundo o tipo de informação recebida sobre aleitamento materno (Viçosa, MG, 1997/1998). 
A maioria das puérperas demonstrou desinformação acerca de uma questão habitual na lactação, o ingurgitamento mamário (Figura 2). Segundo Barros et al. (1994), o desconhecimento das mulheres quanto às formas de prevenir e resolver os problemas comuns no início da amamentação ocasiona o seu insucesso. Para Martins (1998), a mãe, por não conhecer o que pode vir a acontecer, ou até mesmo por já ter conhecimento das intercorrências mamárias, como "leite empedrado" e " rachaduras no bico do peito", e por considerá-las um fato normal do aleitamento materno, acaba sofrendo desnecessariamente, pois muitas destas situações podem ser evitadas, caso ela receba orientações eficazes.

Sobre a produção e liberação do leite materno (Figura 3), 62,2\% das puérperas reconheceram a existência de fatores que estimulam a produção de leite. Entretanto, apenas 1,5\% citou o estímulo da sucção como um desses fatores. A mãe, ignorando o papel desta prática, muitas vezes substitui ou complementa as mamadas, gerando, com isso, menor estímulo à produção láctea, com conseqüente declínio na amamentação.

Quanto ao conhecimento de outras funções do leite materno além de alimentar a criança, 40,6\% das puérperas mencionaram a proteção contra doenças, e aproximadamente $50 \%$ não souberam informar ou as desconheciam (Figura 4).

Sobre os benefícios da prática do aleitamento materno para a mãe, $74,8 \%$ das puérperas disseram ignorar alguma vantagem proporcionada a elas pela amamentação. Quando a resposta foi afirmativa, o benefício destacado foi a proteção contra o câncer de mama. Em estudo realizado por Carvalhais \& Simões (1997), $52,5 \%$ das mães disseram que o aleitamento materno prevenia o câncer.

Com relação às leis de proteção à nutriz trabalhadora, $84,6 \%$ das entrevistadas não as conheciam. Também, Carvalhais \& Simões (1997) encontraram resultado semelhante quando verificaram que $81,0 \%$ das mães pesquisadas desconheciam estas leis.

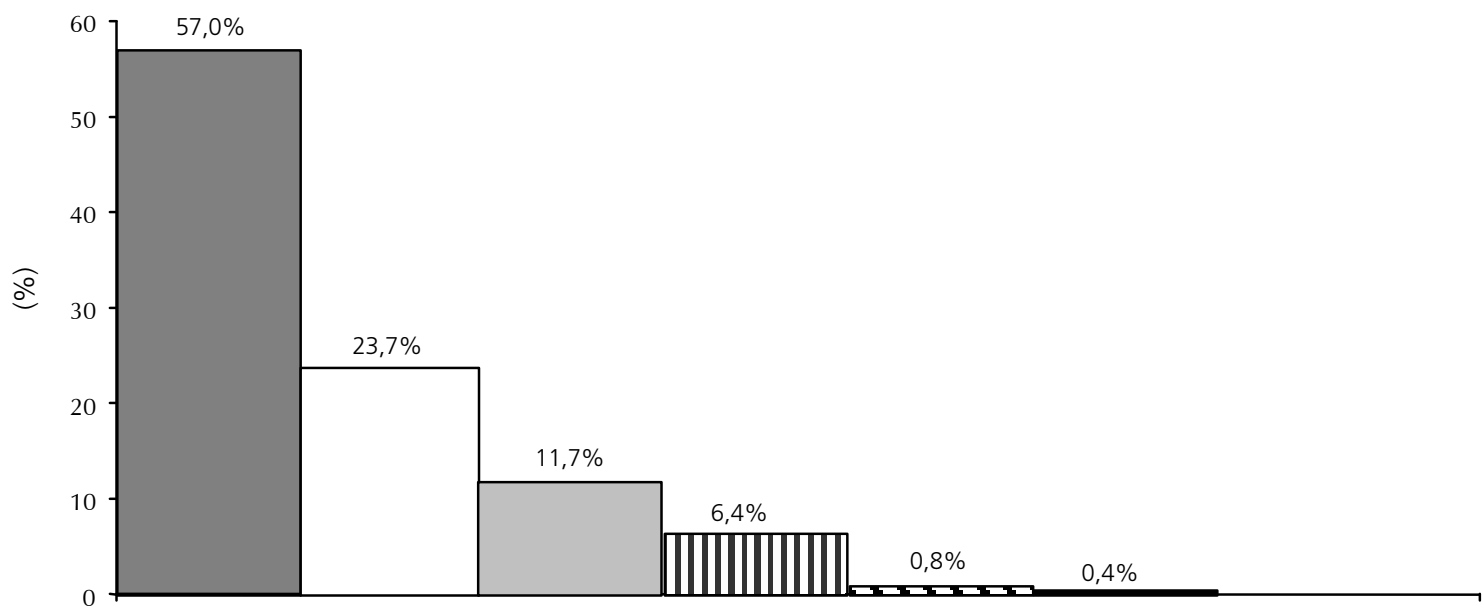

Figura 2. Distribuição da puérperas segundo suas respostas quanto aos cuidados com a mama ingurgitada (Viçosa , MG, 1997/1998). 


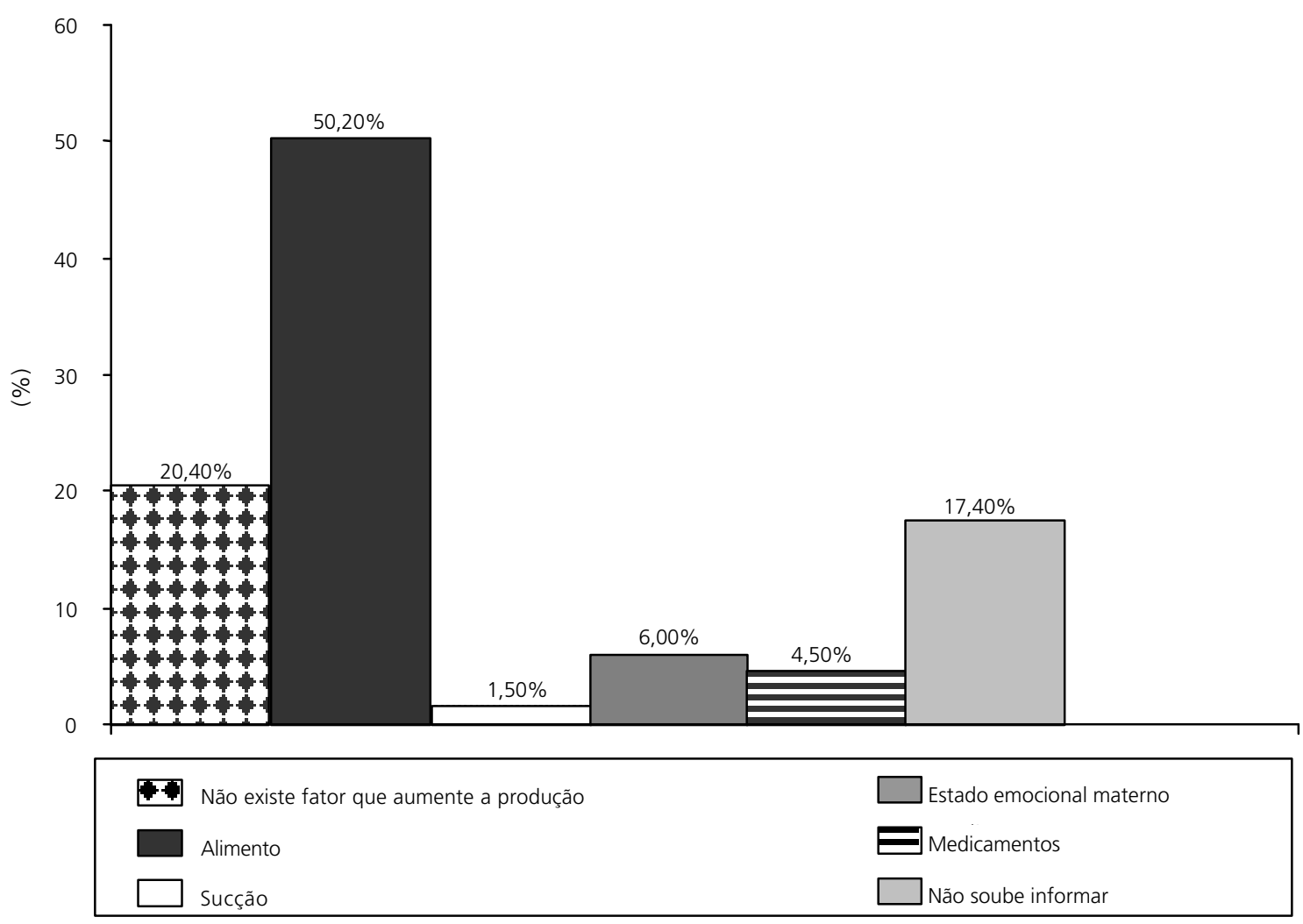

Figura 3. Distribuição de puérperas segundo suas respostas sobre os fatores que estimulam a produção do leite (Viçosa, MG, 1997/1998).

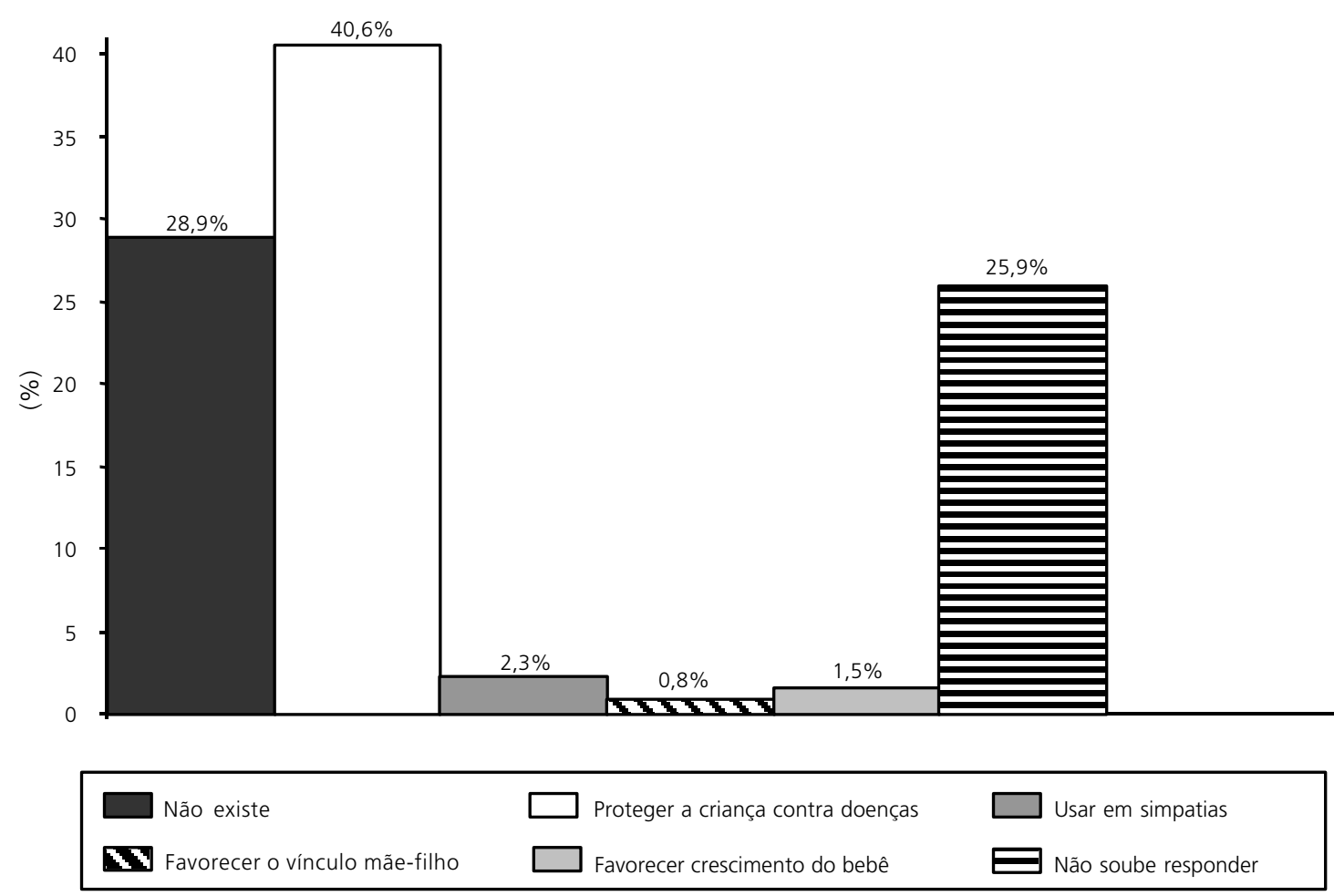

Figura 4. Distribuição de puérperas segundo suas respostas quanto às funções do leite além da alimentar (Viçosa, MG, 1997/1998). 


\section{O N CLUSÃO}

Concluiu-se que, apesar de as puérperas saberem da importância do aleitamento materno para o adequado crescimento e desenvolvimento da criança, elas desconheciam questões simples sobre a prática da amamentação, como técnica de sucção, cuidados e preparo da mama para a lactação, papel da sucção na produção e liberação do leite materno, propriedades e funções do leite e até mesmo benefícios do aleitamento materno para a mãe.

O baixo nível de conhecimento verificado e a escassez de informações recebidas sobre amamentação, bem como o desconhecimento das mães sobre as leis de proteção à nutriz, sinalizam para a urgência de um programa de orientação e promoção do aleitamento materno e orientação da gestante durante o pré-natal.

\section{REFERÊ NCIAS B I B L IOGRÁ F I C A S}

ALMEIDA, J.A.G. Amamentação: um híbrido natureza-cultura. Rio de Janeiro: FIOCRUZ, 1999. $120 p$.

ARANTES, C.I.S. Amamentação: visão das mulheres que amamentam. Jornal de Pediatria, Rio de Janeiro, v.71, n.4, p.195-202, 1995.

BARROS, C.F., HALDERN, R., VICTORA, C.G., TEIXEIRA, A.M.B., BÉRIA, J.U. Promoção da amamentação em localidade urbana da Região Sul do Brasil: estudo de intervenção randomizado. Revista Saúde Pública, São Paulo, v.28, n.4, p.277-283, 1994.

BRASIL. Ministério da Saúde. Como ajudar as mães a amamentar. Brasília, 1994. 177p.

CARVALHAIS, C.K.O., SIMÕES, M.J.S. Conhecimento das mães sobre o aleitamento materno, em Américo Brasiliense. Alimentos e Nutrição, São Paulo, v.8, p.57-63, 1997. (Fascículo único).

FADUL, F.D., XAVIER, L.F. Fatores que contribuem para o desmame precoce. Revista Brasileira de
Enfermagem, Brasília, v.36,n.2, p.213-220, 1983.

GIUGLIANI, E.R.J., ROCHA, V.L.L., NEVES, J.M., POLANCZYK, C.A., SEFFRIN, C.F., SUSIN, L.O. Conhecimentos maternos em amamentação e fatores associados. Jornal de Pediatria, Rio de Janeiro, v.71, n.2, p.77-81, 1995.

KISTIN, N., BENTON, D., RAO, S., SULLIVAN, M. Breastfeeding rates among black urban low-income: effect of prenatal education. Pediatrics, Evanston, v.86, n.51, p.741-746, 1990.

KOCH, R.M. Cuidados na amamentação: conhecimentos de um grupo de primíparas de parto hospitalar, em Curitiba. São Paulo : Cultura Médica, 1979. p.126. Dissertação (Mestrado) - Escola de Enfermagem, Universidade de São Paulo, 1979.

MARTINS, R.C.B. Aleitamento com êxito sob a perspectiva da nutriz. Ribeirão Preto, 1998. p.130. Dissertação (Mestrado) - Escola de Enfermagem de Ribeirão Preto, Universidade de São Paulo, 1998.

MOURA, E.F.A., ARAÚJO, V.L.C. Aleitamento ao seio: resultado de inquérito realizado junto a pacientes internados na maternidade do hospital da Santa Casa de Misericórdia do Pará. Jornal de Pediatria, Rio de Janeiro, v.56, n.3, p.120-122, 1984.

PESQUISA NACIONAL SOBRE DEMOGRAFIA E SAÚDE. Amamentação e situação nutricional de mães e crianças. Rio de Janeiro : Benfam, 1996. p. $125-138$.

VALDÉS, V., SANCHIEZ, A.P., LABBOK, M. Manejo clínico da lactação: assistência à nutriz e ao lactente. Rio de Janeiro: Revinter, 1996. 128p.

XAVIER, C.C., JORGE, S.M., GONÇALVES, A.L. Prevalência do aleitamento materno em recém-nascidos de baixo peso. Revista de Saúde Pública, São Paulo, v.25, n.5, p.381-387, 1991.

Recebido para publicação em 17 de novembro de 1999 e aceito em 7 de março de 2001. 